\title{
Environmental Accounting as a Tool for Environmental Management System
}

\author{
${ }^{+}$SEETHARAMAN, A; MOHAMED ISMAIL; SARAVANAN, A S
}

\author{
Faculty of Management, Multimedia University, 63100 Cyber Jaya, Malaysia \\ Email: seetha@mmu.edu.my
}

\begin{abstract}
This paper reviews about the relationship of environmental accounting and environmental management system in order to determine the sustainability of organization. In past, the traditional approach of operations management has been used to evaluate an organization's performance based on cost, quality and profit without giving due consideration in preserving the environment. It also identified the lack of awareness and interest by organization about environmental preservation distinguish the context for environmental management needs in developing and newly industrialized countries compared to western countries. However, the growing awareness and pressure by community, customer, and stakeholders has forced the organization to accept the introduction of environmental protection measures into their organization. The integration of environmental accounting into EMS will be served as a self-regulatory compliance to legal and regulation requirement, to reduce cost from customer audits, better market impression, increase efficiency of resources and the ability to adopt changing circumstances would contribute to the improvement of quality performance and organization's performance as a whole. Some of the possible benefit from environmental audit also discussed. In this paper, also discusses number of pollution prevention strategies. It concludes with an emphasis on the use of environmental accounting for continuous improvement in environmental corporate policies and programs by taking into account the regulatory, technical developments, scientific developments, and it must be fully integrated into EMS along with other functional area. @JASEM
\end{abstract}

There is a worldwide debate on the issue of environmental management, stemming from a flow of evidence about ecological degradation caused by economic development (Taylor, et al., 2001). Now, due to cost pressures, customer awareness, supply chain relations and activities of environmental campaigners encourage the companies to go for environmental initiatives (Perry \& Sheng, 1999). The society particularly from developed countries highly concern about the impacts on the quality of their life due to the pollution of air, land and water. However, the same concern is rather slow in developing countries including Malaysia. To prevent future violations of environmental conservation, regulatory bodies have enacted many laws pertaining to environmental protection including Malaysia but the effectiveness of these regulations is yet to be seen.

External pressures such as legislation and public concern, as well as market opportunities arising from environmental concerns, have compelled firms to integrate environmental issues into their strategic planning process literature by describing organization participation in a wide range of environmental activities in a number of industry sectors (Banerjee, 2001). Pun et al., 2002, characterized the assessment of organizational effectiveness through seven critical questions:

Email: seetha@mmu.edu.my
- What is the purpose of assessing organizational effectiveness?

- What level of analysis is being used?

- From whose perspective is effectiveness assessed?

- What is the assessment focus on the main domain of activity?

- What time frame is being employed?

- What types of data are being used in assessment?

- What is the reference against which effectiveness is being judged?

The answer to these questions can provide insightful means to evaluate the applicability of the proposed five stages framework for environmental management system [EMS] (Figure 1).

Research Problems: In the context of environmental disclosure in companies annual report, it has been noticed and reported that there are:

- Lack of awareness and understanding on the nature and extent of the adoption of environmental management system practices and the relationship between the adoption of these practices and organization's environmental accounting function.

- Lack of understanding and commitment of companies for the needs in the environmental disclosure 
The objectives of the research are:

- To determine and asses the effect of environmental accounting on the improvement of environmental and overall organization's performance
- To determine the extent of environmental disclosure as a part of social responsibility

- To determine the effectiveness of environmental cost accounting system for environmental audits and performance improvements

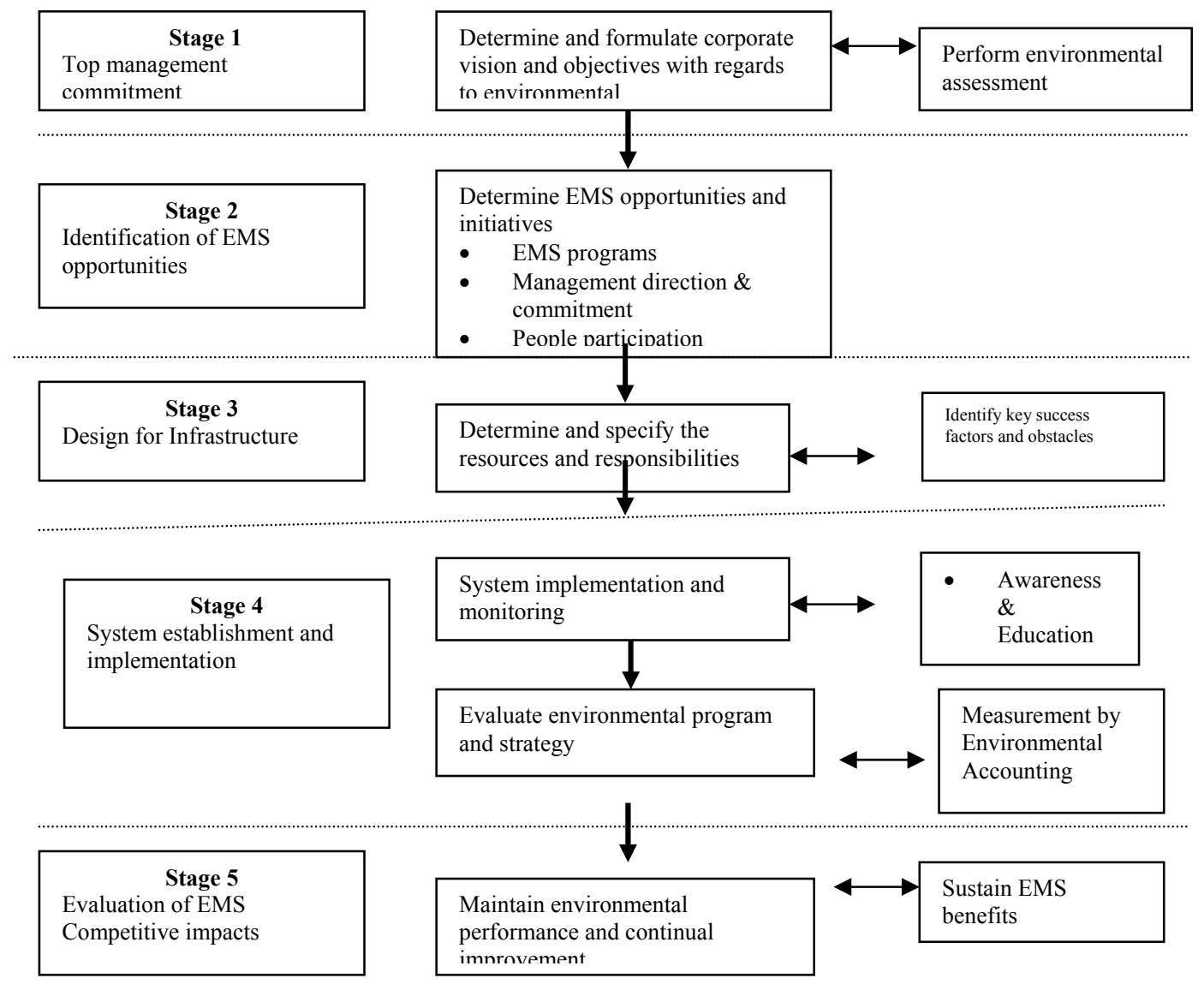

Figure 1: Framework of EMS Planning (Source: modified from Pun et al., 2002)

This study focuses on the use of environmental accounting system to monitor the baseline parameters in the environmental management system as an effective tool to monitor and evaluate organization's commitment to environmentally sustainable forms of business activity.

\section{Survey of Literature}

Alan S. Dunk (2002) investigates the extent to which product quality and the implementation of environmental accounting positively influence quality performance. He suggested that the integration of environmental issues into financial decision processes by using environmental accounting would contribute to the enhancement of quality performance and firm performance as a whole. Even though, the author statistically proved his hypothesis that the implementation of environmental accounting and product quality positively affects quality performance $\left(\mathrm{R}^{2}=0.212\right.$ or 21.2 percent can be explained by this model), he did not determine the other factors that may implicate quality performance. In addition, the author did not test his hypothesis in other geographical areas that can support integrated approach in managing environmental accounting and product quality.

D. Senthil Kumaran, S.K. Ong, Reginald B.H. Tan, A.Y.C. Nee (2001), discussed about the life cycle environmental cost analysis (LCECA) model that 
include eco-costs into the total cost of the products. Eco-costs are associated with both direct and indirect costs of the environmental impact caused by the product in its entire life cycle. The authors also described how the LCECA model could be used to identify the feasible alternatives for cost-effective, eco-friendly parts/products. This attempts to incorporate costing into the life cycle assessment (LCA) practice, which is a systematic evaluation of the needs and opportunities to reduce the environmental burdens associated with energy and raw material use, and waste emissions throughout the life cycle of a product, process or activity. In addition, the authors also showed about the mathematical model of LCECA that aims to define the correlation of the various eco-costs with the total cost. This model has been converted into a computational LCECA model, to compare the ecocosts of the alternatives. The current limitation of the LCECA model discussed by the authors proved that the model is not able to provide the full range of possible outcomes that would result from variances in the cost estimates.

Farhad Analoui and Azhdar Karami (2002), explore about the chief executive officers' (CEO) perception of the environmental scanning in relation to the firm's performance in SME sector in the context of the British electrical and electronic firms. The authors disaggregated the SME sector into three components, which are micro-enterprises, small enterprises and medium enterprises. Not surprisingly, it is widely viewed as the first step in the process of strategic management. It is concluded that there is a significant relationship between increasing environmental scanning of the firm, and the success of firm performance in small and medium sized enterprises. The weakness of this article is that the authors did not include environmental management as part of environmental scanning parameters study for the CEOs to consider in managing their firm.

Gluch, Pernilla (2000), has two aims in this paper, which are; to evaluate the use of costs of environmental errors (CEE) as a managerial environmental accounting tool, and to explain theoretically why 'new' environmental tools, such as CEE are continuously being developed. He used the CEE concept to measure the financial environmental consequences caused by construction industries in Sweden. CEE is used to identify the errors and related causes and costs to the environmental where the author has identified 243 errors and 78 different kinds of causes. CEE is concluded as a powerful tool to measure the negative derivatives and subsequently

an improvement area could be identified. In this article, the limitation is that CEE focus on costs and not on benefits, implying that CEE has poor extensibility as an environmental decision-support tool.

Gregory Theyel (2000) explores whether there are discernible differences in the environmental innovation and performance of US chemical firms that can be explained by differences in the management practices and characteristics of the firms. Using data from a national survey, firm visits, and phone interviews, the author assesses the pervasiveness of the adoption of environmental management practices in the two important sectors of the chemical industry. These two sectors, namely plastic and resins and ink manufacturing plant were identified as two of the top ten most polluting sectors by volume and the top two by carcinogenicity. The limitation in this article is that the author focuses on the environmental innovation and performance and not on the environmental sustainability over time.

Hoda F.S. Rizk, Ahmed A. El-Abssawy and Mamdouh I. Khoder (2002), presented about the serious effect of insecure pesticides to the surface ozone $\left(\mathrm{O}_{3}\right)$ as a secondary pollutant resulting from some photochemical reactions during the sunny days which cause a high increase in surface ozone concentration in the ambient air and accordingly increases the dangerous smog level concentration. Ozone is considered as a product of the photochemical oxidation of carbon monoxide in presence of NOx clarified the radical and vital role of the solar radiation and nitrogen oxides on the surface ozone formation. The temporal variation in $\mathrm{O}_{3}$ concentrations due to pesticide spray, the corresponding temperature and relative humidity have been monitored and discussed. Moreover, temperature and relative humidity have significantly influenced ozone concentrations with positive and negative correlation coefficients, respectively. The authors concluded that the use of poisonous pesticides might provide an insecure source of surface ozone particularly in the agricultural area in Egypt. In this article, the authors did not propose any measures to protect the agriculture without affecting the ozone. Hutchinson, Paul D (2000), highlighted about the impact of environmental issues, the role of Environmental Protection Agency (EPA) in implementing the environmental regulatory and the environmental reporting in the United States. In 1996, EPA has identified over 36,000 hazardous waste sites where 1,405 sites classified under National Priorities List (NPL) to cleanup. The total 
(6)

expected cost to cleanup these sites due to ignorance about the impact to human in the past can reach as high as $\$ 500$ billion to $\$ 1$ trillion over the next 50 years. The limitation of this article is that the strategies to minimize the environmental pollution in United States via EPA enforcement have been discussed briefly but it failed to explain the effectiveness of these strategies in controlling the environmental pollution. It also failed to comment on the SEC enforcement's effectiveness in the environmental disclosure by the firms' in their annual financial statement and how SEC communicate this matter to EPA.

Kit-Fai Pun, Ip-Kee Hui, Henry C.W. Lau, Hang-Wai Lau and Winston G. Lewis (2002), discussed about the increasing consciousness of sustainable development and reconciling production with ecosystem conservation have fostered the adoption and implementation of environmental management system (EMS). The authors have investigated the critical processes and factors that have effect on EMS planning in Hong Kong. The framework can be modified to cater for varied business nature and operations in industry. In this article, the empirical findings suggest that the are several characteristics and factors contributing to the success in the EMS planning process such as visible management commitment, integrated management structure, formulation of environmental strategies, recognition and adjustment of organizational ability and recognition and adaptation of environmental initiatives.

Kostas Karatzas, Nicolas Moussiopoulos and Agis Papadopoulos (2001), discuss about the use of the World Wide Web (www) as an information platform for dissemination of environmental information among the public. This article also discusses the results of the IRENIE Environmental Telematics project in Athens, Greece, including the Web-based geographical information system and its configuration. This specific project involves the application possibilities mentioned above, while integrating environmental monitoring, modeling and mapping over the Internet. This project provides services to wide range of government and nongovernment organizations particularly in Europe, by using the European Environmental Information and Observation Network EIONET (URL 2). The results discussed here demonstrate a significant increase in the capabilities of relevant authorities to advance their environmental management potential and to better inform the sensitive members of the public on potential health hazards. There is lack of proof to determine whether relevant authority has used this system effectively to improve the air quality.

Martin Perry and Teng Tse Sheng (1999) studied the trends related to environmental disclosure by companies in Singapore compared to western companies. Information on environmental disclosure in Singapore is presented from a review of organization annual reports (covering two years $1995 / 96$ and 1996/97) and the responses to a postal questionnaire survey covering 252 of 264 public listed companies in Singapore. It is an indicator of business commitment to environmental improvement to the extent that the disclosures report progress in implementing environmental programs. Even though, the possible public policy responses and options for changing current business attitudes toward disclosure are outlined but the authors did not gave any concrete proposal to improve the current rate of disclosure by companies in Singapore. Without any solid actions the companies are unlikely to invest in reporting without a perceived benefit.

Mort Dittenhofer (1995) describes the quantitative information on environmental issues required by management and the auditing team to protect the organization. In this article, the author discuss about environmental accounting and environmental auditing process. He pointed out that both internal and external auditors could perform environmental auditing. In this article, the Clean Air Act of 1990 for an emission right's to pollute environment at a limited rate also been discussed. He also listed out thirteen strategies for conducting an effective environmental audit either by internal or external auditors. In addition, the author explained briefly the categories of environmental audits. In this article, the author does not clearly point out the use of the audit and accounting activities to identify and measure potential environmental problems and their related liabilities. Norman Myers (1998), overviewed some of the emergent issues related to macroeconomics in environmental. He explains about five leading categories and four semi-leading categories related to the economic forces at work. Firstly, look for future environmental costs, which will be very much greater if today's economist not looking beyond the purview of modern economic. Secondly, the sizeable financial transaction daily will lead to more destruction to environment. Thirdly, an increasing number of developing nations are undertaking measures to keep their economic and financial noses above water under the Structural Adjustments Programs by exploitation of their natural resources. The fourth category is the perverse subsidies, which lead to potential 
environmental degradation. The last category is the consumption habits of the rich that disproportionately degrade the global environment for rich and poor alike. The author also reviewed briefly the four semileading categories which are market restrictions imposed by developed nations on developing nations; the insurance industry and global warming; the population growth and the relation to the costs of inaction; and lack of feedback systems to warn against impending crisis or breakdown.

Peter Letmathe and Roger K. Doost (2000) attempts to demonstrate how to use an environmental cost accounting system for internal and external audits and performance improvements. They also briefly explained about five steps to reduce environmental costs namely setup EMS system to identify significant cause and environmental impacts (inputrelated, process-caused and product-cause environmental impacts), determine the flow cause significant impacts, quantify the material and energy, evaluate their realistic costs and determine the causing objects correctly. In this article, the authors did not explain the success of this system in the companies using any statistical data. Roy Gray (2001) briefly outlines what he believed in the three strands of social accounting. As conclusion, he has listed out few key lessons that everyone should learn and retain from the thirty-year of social accounting that are use of silent social accounts, voluntary social reporting, availability of systematic social accounts and ability to monitor and respond to social changes which is highly needed. The limitation of this article is that the possible self-interest of so-called independent bodies is not examined and assessed for their integrity in reporting for social audit.

Subhabrata Bobby Banerjee (2001), discussed about the range of strategies regarding to the environmental issues that can give impact on the organizations' business activities. The author had examined and described a range of environmental strategies taken by 250 USA firms which belong to a variety of industries that include manufacturing firms, chemicals, electronic, food, consumer products, utilities and pharmaceuticals. He described four integrated environmental strategies at different levels, namely enterprise strategy, corporate strategy, business strategy and functional strategy. The setback of this article is that the lists of environmental activities discussed are not comprehensive but rather addressing some basic areas of environmental activities.
Zabihollah Rezaee and Rick Elam (2000) discussed a substantial number of environmental laws and regulations, which have been enacted to hold businesses accountable for their environmental responsibilities. He further mentioned in his introduction that the growing interest in environmental concerns by the public, government, and business community, environmental accountability has become an important issue. Currently, there are two significant types of environmental accountability; mandatory requirements where the corporations must comply with applicable governmental laws and regulations, and voluntary initiatives as an integral part of social responsibilities. The authors also presented a step-bystep implementation plan (15-step process) to adopt adequate and effective environmental management system, conduct proper environmental audits, and successfully become registered to ISO 14001. Zabihollah Rezaee, Joseph Z. Szendi and Rajesh Aggarwa (1995), discussed about the corporate governance and accountability over the reporting and disclosure of environmental cost and their obligations. The legislative efforts through the USA Environmental Protection Agency (EPA) pertaining to environmental issues are generally directed towards control of contamination, clean up of contamination, environmental hazards in the workplace, injury to public health and recovery of damages. Despite the establishment of environmental reporting standard and hefty penalties, the strategies in ensuring the corporate exercised effective environmental accounting, as preventive measures were not discussed.

Research Methodology: Environmental accounting research model in manufacturing industry (Figure 2) was used to determine and establish the monitoring and measurement system for environmental accounting system. In this model, the environmental accounting is used to monitor and measure the four main environmental parameters namely air emission, water, land and noise pollutions. It also used to monitor and measure the environmental impact generated in all relevant processes (environmental impact potential). These environmental data system will give the organization the opportunity to review its improvement activities through appropriate allocation of resources to the environmental initiatives.

\section{Discussion, Analysis and Finding}

Environmental Management System (EMS): An EMS is an integral part of an overall management system that includes organizational structure, planning, 
objectives, activities, responsibilities, procedures, processes and resources for developing, implementing, achieving, reviewing and maintaining environmental policy (definition in ISO14001: 1996 standard; clause 3.5). An EMS serves as a systematic approach in managing the environmental aspects of the business. In EMS, the system is able to improve the environmental performance (Theyel, 2000) in many ways such as stressing on pollution prevention, reduction in cost, compliance with environmental legislation, and improving corporate image. Different regions and countries may adopt different standards for EMS such as ISO9000, QS 9000, SA 8000, BS 7750 (Pun, et al., 2002) but the prominence system adopted by international communities in relation to environmental management is ISO14000 series. The benefits of EMS are served as self-regulatory compliance to legal and regulatory requirements, to reduce costs from customer audits, better market impression, to increase efficiency of resources and the ability to adopt changing circumstances.

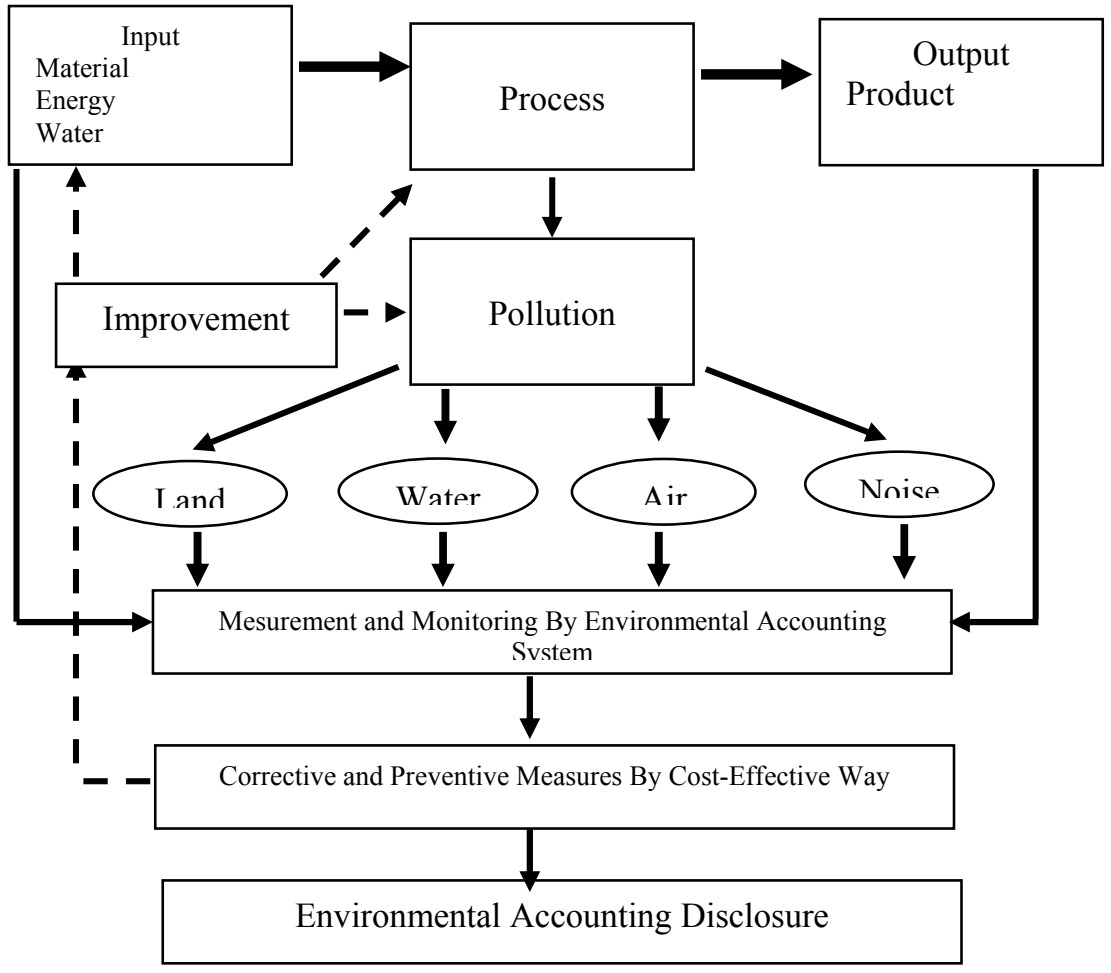

Figure 2: Environmental Accounting Research Model in Manufacturing Industry

Now we are facing many global environmental issues such as global warming (greenhouse effect), ozone depletion, acid rain, deforestation and pollution (land, air, water and noise.). In minimizing these effects the international communities have developed many global environmental agenda aroused due to global environmental concerns such as The Montreal Ozone Protocol addresses issues related to CFCs (1987); The Rio Earth Summit (1992); The Brubdtland Report - Sustainable Development (1987) and The Kyoto Convention- Greenhouse Effect (1997). But the issue is that whether these agendas do help the world to sustain the environment with volunteer participant particularly the industries, which are still unclear particularly in Malaysia.

Environmental Accounting System: As environmental management in business has evolved over time, interest has grown in developing a better understanding of environmental-related financial costs and benefits as input to conventional management accounting. The main stimulus is growing evidence that focus on environmentalrelated factors can enhance the profitability and financial position of a business. Environmental accounting is used to assess full environmental costs associated with activities and/or products. 
Environmental accounting also can be used to track environmental performance of organizations' in more measurable manner. The key areas for monitoring are aggregated emission to air, water effluent discharge, soil contamination and boundary noise level as indicated in Figure 2.

In the past, environmental accounting systems were used as a tool to evaluate and disclose environmental impact reduction effects to environmental conservation costs. However, in fact now the EMS in business has evolved, interest has grown in developing a better understanding of environmental- related financial costs and benefits as an input to conventional management accounting. For example, the internal costs associated with air emission to the environment are often not identified within conventional management practices. As a result, cost savings relating to environmental pressures frequently remain hidden. These so-called hidden costs are difficult to detect, yet these costs are often chronic in character and can be significant (Pernilla, 2001). Further to that, many other compelling reasons why the organizations need to establish and adopt the environmental accounting are shown in Figure 3.

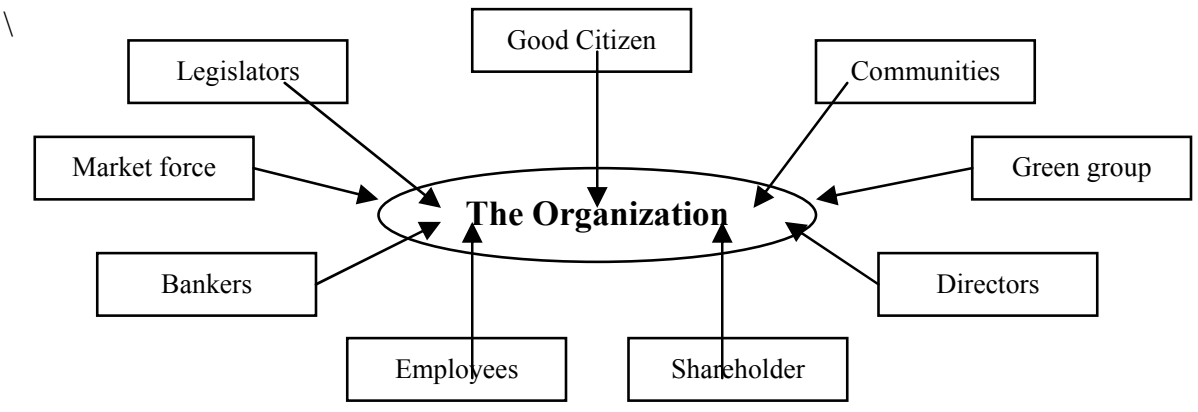

Figure 3: External Pressure on Organization (Source: Medley, 1997)

Most companies had recognized the superiority in principle of pollution prevention (Theyel, 2000) at source over end-of-pipe solution, and were seeking to prevent pollution by integrating EMS into their complex environmental decision-making processes (Pernilla, 2001), which eventually lead to sustainable management. It is, however, necessary for this tool to internally measure and evaluate the profit obtained from business activities and the environmental impact appropriate for an organization's business size. As shown in Figure 2, it is necessary to measure and identify the environmental cost impact generated in all relevant processes (environmental impact potential) such as air emission, waste disposal, waste water. The organizations need to identify the environmental impact potential and environmental influences in each process and measures and evaluates the managerial resources appropriately allocated to the environmental influences. The organizations also need to measures and evaluates environmental conservation costs paid by product line and process, whether the costs work toward advancing social effects and corporate profits, and whether the environmental impact of business activities as a whole suits the organization's business size which leads to the establishment of a framework for environmental accounting.
The Institute of Management Accountants has identified the recognition and disclosure of environmental costs as a priority item on its list of important emerging management accounting information and cost recognition issues (Dunk, 2002). Meanwhile, the representative of an environmentally oriented association of enterprises (BAUM), estimated in 1997 that companies could reduce by $5 \%$ their total costs with a decisionoriented EMS (Letmathe and Doost, 2000).

Environmental Accounting Disclosure in Annual Report: Though many countries have some sort of regulation for the environmental disclosure, for example in the USA, the Securities and Exchange Commission in 1986 address the needs for environmental disclosure (Dittenhofer, 1995). However, regulation for the mandatory reporting by companies in developing and NIEs is still yet to be seen.

Lack of environmental awareness: Sixty eight percent of companies surveyed claimed that their activities had no significant impact toward environment, and therefore there is no need for any disclosures Further, many companies believed that environmental issues 
$\ldots$

are not relevant to their organization and some claimed that environmental impacts are unknown.

Lack of perceived benefit: A large number of nondisclosing companies did not believe that investment in environmental initiative offered them either opportunity for cost saving or improved support from shareholders. Only half existing reporting companies indicating that disclosure would be a regular practice in their annual report further underline this belief.

Lack of government pressure: One of the most prominent factors that are able to drive companies for environmental disclosure is the government. The government enforcement for mandatory environmental reporting is very important. The government is ranked above the influence of business associations and was seen to be more important the resource or shareholders and investors pressure. Strong instruction and enforcement is needed to overcome resistance and perceptions that environmental reporting is an unnecessary cost burden.

Environmental audit: Environmental auditing is a generic term, which encompasses a wide range of management activities, including environmental compliance audit, environmental risk assessments, and environmental review (Rezaee and Elam, 2000). In ISO 14001, environmental audit defined as "the systematic, documented verification process of objectively obtaining and evaluating audit evidence to determine the reliability of an assertion with regards to environmental aspects of activities, events and conditions as to how they measure established criteria, and the communicating such result to the client" (cited in Taylor et al., 2001).

In order to carry out effective environmental audit, the management of organizations must provide adequate resources and financial support. Further, the organization also must ensure the auditors are well qualified to conduct the EMS audit by providing adequate training related to environmental audit. According to Taylor et al. (2001), the best EMS auditor is the auditor with an accounting background.

Pollution Prevention Strategies: The total estimated damage caused to the natural environment in one day according to the Germany Federal Environmental Agency (Letmathe and Doost, 2000) is given by:

- The destruction of 55,000 hectares of tropical forest;

- The reduction of arable land by 20,000 hectares;
- The extinction of 100 to 200 species;

- Emission of 60 million tons of carbon dioxide into the atmosphere

Environmental issues affect different areas of an organization's operation such as manufacturing, raw material procurement, energy usage, marketing, product development, disposal and waste management (Banerjee, 2001). Some of the prevention strategies proposed that could be adopted by organizations is by using prevention strategies as follow:

- Design products, which generate less waste or emission during their life cycle. This can be carried out through conducting life-cycle analysis.

- Technologies that uses less power and produce less waste which subsequently will decrease the expensive "end-of-the-pipe" clean-up operations (Banerjee, 2001)

- Substitute materials that can reduce waste or indirect effect

- Modify operating processes to reduce wastes

- Develop continual waste and energy minimizing program

- Develop method to reuse or recycle waste rather than sent for disposal (recovery). Us

- Conservation - minimize depletion of natural resources by establishing effective control measures or prevention measures

- Use the recycled material

Limitation of Research: In past, many researchers have identified the difficulties or limitations in establishing good environmental accounting are; difficult in forecasting future environmental related cost, type of the likelihood action or effort need to be taken, and failure to see the benefit of environmental accounting to companies. However, in this paper did not test these limitations. Furthermore, the various difficulties and problems faced by the organizations in establishing an environmental accounting not determined. The amount of resource allocation in term of manpower, money and others by organizations towards environmental initiatives needs further investigation. In the area of environmental auditing, the depth of audit conducted either by external or internal auditors in determining the relationship between EMS and the environmental accounting need for further research. In addition, there is no information or data regarding to the question on what is the commitment level of organization's CEO and senior managers towards EMS, particularly in Malaysia. 
$\ldots$

Conclusion: Lately, the relationship between the organization and the environment is receiving increasing attention. Currently, debate on global climatic change and biodiversity is becoming more commonplace in corporate world, together with concern over water, air and soil pollution. Although the sustainability of economical development is a shared responsibility of organization, government and consumers, but the organizations can play vital role in slowing down the environmental degradation. It is possible because an organization has financial resources, technological knowledge and institutional capability and long-term vision to find environmental solutions An organization can contribute towards sustainable environment by innovating and improving their products and processes in order to use raw materials more efficiently, reduce the waste generate from their processes, improve the waste disposal methods and improve the work conditions. Thus, the programs or activities for keeping pollution under control, zero waste or design for environment such as product life cycle analysis (LCA), total quality environmental management and others. In this way, the organization can lead to an improvement in overall environmental performance, customers' satisfaction and company performance.

\section{REFERENCES}

ACCA Malaysia (2002) "The state of corporate environmental reporting in Malaysia" (URL: www.accaglobal.com/sustainability).

Analoui, F. and Karami, A. (2002), "How chief executives' perception of the environment impacts on company performance", Journal of Management Development, Vol. 21 No. 4, pp. 290-305.

Banarjee, S.B. (2001), "Corporate environmental strategies and actions", Management Decision, Vol. 39 No. 1, pp. 36-44.

Dittenhofer, H. (1995), "Environmental accounting and auditing", Managerial Auditing Journal, Vol. 10, No. 8, pp.40-51.

Dunk, A.S. (2002), "Product quality, environmental accounting and quality performance", Accounting, Auditing and Accountability Journal, Vol. 15 No. 5, pp. 719-732.

Gray, R. (2001), "Thirty years of social accounting, reporting and auditing: what (if anything) have we learnt?, Business Ethics: A European Review, Vol. 10, No. 1, pp. 9-15. Blackwell Publishers Ltd.

Hutchinson, P.D. (2000), "Environmental Accounting: Issues, reporting and disclosure", Journal of Applied Business Research, Vol. 16, Issue 4.

Karatzas, K., Moussiopoulos, N. and Papadopoulos, A. (2001), "Web-based tools for environmental management", Environmental Management and Health, Vol. 12 No. 4, pp. 356-363.
Kumaran, D.S., Ong, S.K., Reginald Tan, B. H. and Nee, A.Y.C. (2001), "Environmental life cycle cost analysis of products", Environmental Management and Health, Vol. 12 No. 3, pp. 260-276.

Letmathe, P. and Doost, R.K. (2000), "Environmental cost accounting and auditing", Managerial Auditing Journal, Vol. 15, No. 8, pp. 424-430.

Medley, P. (1997), "Environmental accounting - what does it mean to professional accountants?", Accounting, Auditing \& Accountability Journal, Vol. 10 No. 4, pp. 594-600.

Myers, N. (1998), "Emergent issues of environmental economics - what we should be analyzing closely but haven's thought much about", International Journal of Social Economics, Vol. 25 No. 6/7/8, pp. 1271-1278.

Pernilla, G. (2000), "Costs of environmental errors (CEE)", Greener Management International, Issue 31.

Perry, M. and Sheng, T.T. (1999), "An overview of trends related to environmental reporting in Singapore", Environmental Management and Health, Vol. 10 No. 5, pp. 310-320.

Pun, K.F., Hui, I.K., Lau, H.C.W., Law, H.W. and Lewis, W.G. (2002), "Development of an EMS planning framework for environmental management practices", International Journal of Quality and Reliability Management, Vol. 19 No. 6, pp. 688-709.

Rezaee, Z. and Elam, R. (2000), "Emerging ISO 14000 environmental standards: a step-by-step implementation guide", Managerial Auditing Journal, Vol. 15 No.1 (2), pp.60-67.

Rezaee, Z., Szendi, J.Z. and Aggarwal, R. (1995), "Corporate governance and accountability for environmental concerns", Managerial Auditing Journal, Vol. 10 No. 8, pp. 27-33.

Rizk, H.F.S., El-Abssawy, A.S. and Khoder, M.I. (2002), "An analysis of pesticide impact on air quality, especially surface ozone", Environmental Management and Health, Vol. 13 No. 2, pp. 152-162.

Taylor, D.W., Sulaiman, M. and Sheahan, M. (2001), "Auditing of environmental management systems: a legitimacy theory perspective", Managerial Auditing Journal, Vol. 16 No.7, pp. 411-422.

Theyel, G (2000), "Management practices for environmental innovation and performance", International Journal of Operations \& Production Management, Vol. 20 No. 2, pp. 249-266. 